\title{
DERECHOS DE LAS VÍCTIMAS DE VIOLACIONES A DERECHOS HUMANOS. UNA MIRADA DESDE LA REPARACIÓN INTEGRAL Y EL CUMPLIMIENTO DE SENTENCIAS*
}

\author{
RIGHTS OF VICTIMS OF HUMAN RIGHTS VIOLATIONS. \\ A LOOK FROM THE COMPREHENSIVE REPARATION \\ AND THE COMPLIANCE OF JUDGMENTS
}

\section{Jaime Arturo VERdín PÉREZ**}

RESUMEN: El trabajo que se plantea en las siguientes líneas parte de la inferencia de que existe un vínculo directo entre las violaciones de derechos humanos, la obligación de reparar el daño y el cumplimiento de las decisiones judiciales internacionales que ordenan tal reparación, pues la propia sentencia y su efectivo cumplimiento constituye una forma de reparación hacia las víctimas de violaciones de derechos humanos.

Palabras clave: cumplimiento de sentencias, reparación integral, víctimas, violaciones a los derechos humanos.
ABSTRACT: The work that is proposed in the following lines, starts from the inference that there is a direct link between human rights violations, the obligation to repair the damage and compliance with international judicial decisions that order such reparation, since the sentence itself and its effective compliance constitutes a form of reparation for victims of human rights violations.

Keyzerds: Compliance with Fudgments, Comprehensive Reparation, Victims, Violations of $\mathrm{Hu}$ man Rights.

* Artículo recibido el 24 de julio de 2019 y aceptado para su publicación el 30 de abril de 2020 .

** ORCID: 000-0002-6699-359X. UNAM. Programa de Becas Posdoctorales en la UNAM, becario del Instituto de Investigaciones Jurídicas, asesorado por el doctor Eduardo Ferrer Mac-Gregor Poisot. Doctor en derecho, maestro en derecho constitucional y amparo. Profesor y académico especialista en materia electoral del Posgrado en Derecho de la UNAM. Correo electrónico:jaime.verdin@comunidad.unam.mx.

Boletín Mexicano de Derecho Comparado, nueva serie, año LII, núm. 157, enero-abril de 2020, pp. 333-352. 
SUMARIO: I. Exordio. II. La reparación integral como derecho irrenunciable. III. Elementos de la reparación integral del daño. IV. Cumplimiento de sentencias internacionales como elemento fundamental de la reparación. V. Conclusiones. VI. Bibliografia.

\section{EXORDIO}

Una de las principales preocupaciones en torno a los derechos humanos sin duda alguna la constituye su efectividad; esto significa su posibilidad de realización material, debido a que resultaría ilusorio su reconocimiento y desarrollo dogmático sin que éstos colmen una necesidad de satisfacción humana; de este modo, cobran especial relevancia el derecho a la verdad, el acceso a la justicia y la reparación integral del daño para asistir esta expectativa, sobre todo si consideramos a la víctima en la concepción de los derechos humanos, no así del proceso penal.

En dicho entendido, y para efectos de la presente investigación, constituyen el objeto de estudio las víctimas de violaciones a derechos humanos, entendidas como las personas que sufren una afectación a sus derechos y libertades intrínsecas por un acto de autoridad que menoscaba su dignidad.

Es importante señalar que las víctimas de violaciones de derechos humanos representan la columna vertebral de cualquier sistema de protección; en torno a ellas gira la mayor parte de las necesidades que debe contemplar el mismo, especialmente las encaminadas al acceso a la justicia, considerando la existencia de un recurso judicial efectivo, y adicionalmente éste contenga las garantías mínimas de un proceso justo o debido proceso.

Según Jorge Witker, el concepto de víctima "ha ido variando con el tiempo, dependiendo de la postura asumida por los doctrinarios penalistas", además de señalar que tanto en el sistema universal como en los sistemas regionales de protección de derechos humanos hay un caudal importante de instrumentos que han desarrollado de forma puntual no sólo conceptos en torno a las víctimas, sino además contemplando prerrogativas para su reconocimiento, y sobre todo reparación integral (González y Witker 2019, 233-256).

Si bien no es materia de este trabajo, es importante señalar que dos años después de las tan importantes reformas constitucionales en materia 
de derechos humanos y amparo, en 2013 se publicó en el Diario Oficial de la Federación la Ley General de Víctimas, cuyo propósito principal era consolidar un sistema que garantice el derecho de las víctimas a la justicia en el estricto cumplimiento de las reglas del debido proceso.

Es de notar que la propia Ley General hace una distinción entre las víctimas del delito y de violaciones a derechos humanos, al señalar en su artículo segundo su objeto, encaminado a garantizar en especial el derecho a la asistencia, protección, atención, verdad, justicia, reparación integral, debida diligencia, y todos los demás derechos consagrados en la misma, así como en la Constitución, en los tratados internacionales de derechos humanos de los que el Estado mexicano es parte y demás instrumentos en derechos humanos.

Para efecto de la Ley, se denominarán víctimas directas aquellas personas físicas que hayan sufrido algún daño o menoscabo económico, físico, mental, emocional, o en general cualquiera puesta en peligro o lesión a sus bienes jurídicos o derechos como consecuencia de la comisión de un delito o violaciones a sus derechos humanos reconocidos en la Constitución y en los tratados internacionales de los que el Estado mexicano sea parte (Ley General de Víctimas, Diario Oficial 2013).

En ese tenor, la víctima de violaciones de derechos humanos deberá tener acceso a un recurso judicial efectivo, legal, constitucional y convencional. De este modo, el planteamiento principal se encamina a determinar la importancia no sólo del acceso a la justicia, incluidos todos los mecanismos al alcance de las víctimas nacional o internacionalmente, sino también su potencial cumplimiento, ya que de poco resultaría útil acudir a instancias que reconozcan las violaciones de derechos humanos por parte del Estado si no alcanzan en sí mismas una reparación integral.

En este contexto, consideramos que la legitimidad de los órganos judiciales también se ve acompañada por el poder de cumplimiento de sus decisiones, las cuales constituyen el vehículo para la efectividad de los derechos connaturales a la persona, pues permiten que cuando los derechos no son respetados exista una garantía eficaz que los haga una realidad material, una fuerza con imperium de ley que los ejecute, pero bajo el principio general de derecho internacional, que dispone que quien causa un daño está obligado a repararlo; esta premisa incluye al Estado (sobre este tema, Petrova 2019). 
De este saber a manera de preámbulo, García Ramírez también distingue los conceptos de víctima del delito y de violaciones a derechos humanos, al indicar que en términos amplios, desde un sistema iuspenalista, víctima conduce a pensar en el sujeto pasivo del delito y a quienes sufren en sentido amplio los efectos desfavorables por la comisión, en tanto que en el plano internacional de los derechos humanos se alude al sujeto lesionado de las violaciones de derechos, reconocidos en los tratados (García 2016).

En ese entendido, el planteamiento que me he propuesto desarrollar en el presente trabajo se vincula con el cumplimiento de sentencias internacionales como un elemento indispensable de la reparación integral del daño, que permite la materialización de los derechos de las víctimas, especialmente al tenor del acceso a la justicia ante tribunales internacionales; es decir, la Corte Interamericana de Derechos Humanos. Cabe resaltar que los mecanismos para exigir el cumplimiento a nivel interno son diferentes, así como los efectos, e inclusive la configuración de responsabilidades (García y Benavides 2014; Pinacho 2019; Nash 2009).

De igual manera, que la verdadera garantía, a través de los procesos judiciales, le posibilita a un órgano de naturaleza imparcial que sanciona a través de sus atribuciones en una sentencia judicial, los abusos del poder, los discursos radicales, los fundamentalismos y las dictaduras, que lesionan las garantías y libertades humanas, a través de los medios procesales idóneos que pongan límite a los excesos del Estado y propicien el equilibrio de los poderes y el cumplimiento de las normas. De este modo, es indispensable dotar a los jueces, de todas las herramientas técnicas para llevar a cabo dichas atribuciones.

Por lo anterior, el trabajo que se plantea en las siguientes líneas parte de la inferencia de que existe un vínculo directo entre las violaciones de derechos humanos, la obligación de reparar el daño y el cumplimiento de las decisiones judiciales internacionales que ordenan tal reparación, pues la propia sentencia y su efectivo cumplimiento constituye una forma de reparación hacia las víctimas de violaciones de derechos humanos.

En ese entendido, es obligatorio el análisis de la reparación integral del daño en su doble dimensión, tanto como derecho fundamental exigible e irrenunciable de las víctimas, sobre todo cuando deriva de un fallo judicial internacional con fuerza normativa, así como en su carácter de obligación del Estado en el cumplimiento de sus compromisos constitu- 
cionales y convencionales vinculados con el deber de respeto y garantía consagrados tanto en la Constitución en su artículo 1o. como en la propia Convención Americana sobre Derechos Humanos, artículo 1.1.

La importancia de dicho tema es enfatizada si consideramos que la Corte Interamericana de Derechos Humanos finalizó el 2019 con 223 casos contenciosos, en etapa de supervisión de cumplimiento de sentencia que implica la supervisión de 1,153 medidas de reparación, del total de los 314 casos sometidos ante este tribunal hasta diciembre de 2019, lo que constituye sólo el 29\% del cumplimiento de dichas resoluciones y motiva la preocupación (Corte IDH, Informe Anual 2019).

El propio tribunal de derechos humanos señala que tanto el número de reparaciones ordenadas como su naturaleza y complejidad de cumplimiento impacta en el tiempo que un caso puede estar en la etapa de supervisión de cumplimiento (Corzo 2013; Hitters 2011; Londoño 2005).

Desde esta última perspectiva, el concepto de la reparación integral del daño constituye un elemento esencial, que permite evaluar la eficacia del fallo internacional, en la medida en que él mismo consiga o no por un acto judicial la restitución plena de los derechos de las personas (restituto in integrum); por lo tanto, puede sugerir indicadores que provean de elementos para calificar de eficaz o ineficaz una resolución internacional, y que abarquen - inclusive - el escenario sobre el cumplimiento de las resoluciones emitidas por órganos supranacionales, su tarea y los posibles desafíos a los que se enfrenta.

Así, podríamos señalar que la obligación de "reparación" presupone la existencia de una violación a los derechos humanos, lo que significa que su surgimiento se encuentra sujeto a la condición necesaria de que se hayan incumplido obligaciones primarias de tutela a los derechos humanos (Saavedra 2013). Esto es, las obligaciones a cargo de los Estados de promover, proteger, respetar y garantizar los derechos humanos no se ven satisfechas.

Sobre el particular, conviene plantearse cuáles son las maneras en que el derecho deberá enfrentar el cumplimiento de los derechos fundamentales desde las tareas primigenias contenidas en la Constitución, para posteriormente discutir sobre la reparación integral del daño y su análisis dogmático a partir del concepto de víctima, que se encuentra vinculado a la materia penal, pero que ha sufrido una transformación plausible con el 
devenir de los tiempos para dar cabida también a las víctimas de violaciones de derechos humanos.

Cabe señalar que uno de los principales desafíos de la Corte Interamericana lo constituye el cumplimiento de sus resoluciones; es así que, con el fin de efectuar la supervisión de cada caso, desde 2015 entró en funcionamiento una unidad de la Secretaría de la Corte dedicada exclusivamente a dicha función; desde luego, no quedan ajenas las audiencias y resoluciones de supervisión de cumplimiento, cuyo impacto ha sido decisivo para la eficacia de la sentencia internacional.

Con base en lo que se acaba de decir, este documento, a pesar de lo sintético, pretende identificar inicialmente que las víctimas de violaciones a derechos humanos cuentan con derechos irrenunciables, en especial desde el análisis de la protección judicial, y que se encuentran ligados a su dignidad humana, a los valores intrínsecos de la persona y a la aspiración de justicia.

Sobre todo, tales derechos irrenunciables se encaminan a instrumentar procedimientos jurídicos y administrativos destinados a hacer justicia y conceder una reparación integral del daño ocasionado por el Estado, cuya finalidad no sólo sea garantizar en su carácter individual o colectivo, sino también a evitar que las autoridades en el ejercicio del poder público vuelvan a cometer un daño, violentando con ello las normas internacionales en derechos humanos.

En este sentido, diversos pronunciamientos han mencionado que

... las reclamaciones de reparación por violaciones flagrantes de los derechos humanos no se encuentran sujetas a prescripción y que no pueden excusarse en el mero paso del tiempo (fundamento de la prescripción) para no dar cumplimiento a sus obligaciones internacionales de investigar, sancionar y reparar las graves violaciones a los derechos humanos. ${ }^{1}$

Así, el concepto de víctima quedaba limitado a la persona que resiente la afectación del daño por parte de otro particular, y su exigencia se circunscribía a dicha condición; sin embargo, este planteamiento, tal como se ha referido, queda superado, correspondiendo actualmente una exigencia al Estado como garante de la preservación del Estado constitucional

1 Órdenes de Guerra y otros vs. Chile, serie C, núm. 372 párr. 92, 2018.

Esta obra está bajo una Licencia Creative Commons

Atribución-NoComercial-SinDerivar 4.0 Internacional, IIJ-UNAM.

Boletín Mexicano de Derecho Comparado, núm. 157, enero-abril de 2020, pp. 333-352. 
de derecho al adoptar sus compromisos internacionales y, desde luego, los plasmados en la propia Constitución.

En este conjunto de referencias es posible entender por víctima en su concepción más amplia la indicada por la Real Academia de la Lengua, que la define como la persona que padece daño por culpa ajena o por causa fortuita (Diccionario de la lengua española, 2018). De este modo, es conveniente recordar que toda violación a una obligación internacional que haya producido un daño comporta el deber de repararlo adecuadamente. El consentimiento de la competencia contenciosa de la Corte Interamericana de Derechos Humanos permite concebir a esta justicia como obligatoria, al igual que sus resoluciones.

En la opinión de Sergio García Ramírez, tal concepto alude al sujeto lesionado o víctima de la violación de esos derechos recogidos o reconocidos por declaraciones y tratados (García y Benavides 2014). Así también, continúa el profesor emérito señalando que anteriormente se deslindó la víctima directa de la víctima indirecta y de la víctima potencial. Aquélla era quien sufría inmediatamente la lesión o el menoscabo de un bien jurídico del que era titular, recogido en un derecho humano. La víctima indirecta, en cambio, resultaba afectada de manera diferente por la violación cometida en contra de la víctima directa: padecía sufrimiento, obstáculos para el acceso a la justicia, quebranto patrimonial, etcétera. Finalmente, la víctima potencial era el sujeto cuyo derecho podría ser vulnerado por la acción del Estado: se hallaba, pues, en situación de riesgo o peligro (García y Benavides 2014).

Se puede considerar que la existencia de este concepto se vincula directamente a todas las actuaciones procesales a través de las cuales una persona ejerce un derecho y hace valer a su vez los derechos que han sido reconocidos por tratados internacionales y por la propia Constitución, y que por una actuación irregular del Estado se han visto violentados. Esto nos lleva a pensar en que el órgano internacional, a través de la condena que emite y considera indispensable la reparación, identifica por un lado la titularidad de esa exigencia a una persona denominada víctima, y por el otro la obligación del Estado.

Siguiendo la línea de García Ramírez en el caso Myrna Mack Chang, en su voto concurrente, afirma que "la protección de la víctima - y desde luego la prevención de las violaciones a los derechos humanos de todas las personas - constituye el desiderátum del sistema interamericano y la 
razón de ser de las instituciones que concurren bajo este rubro, como la Corte Interamericana". ${ }^{2}$

En esa lógica, la perspectiva de diversos instrumentos internacionales, entre ellos el de la Declaración Universal de los Derechos Humanos, nos obliga a poner de manifiesto a los derechos de las víctimas a la luz del proceso consciente de reconocimiento de las prerrogativas fundamentales a nivel nacional e internacional desde una dimensión, no sólo dogmática, sino sobre todo procesal; esto es, el derecho a la reparación del daño es un derecho humano y un derecho procesal indispensable para la dogmática constitucional. Podemos entenderlo como derecho y como garantía.

Jorge Calderón Gamboa señala que

... en el desarrollo de las reparaciones se registra en la práctica que por muchos años tuvo la Corte IDH de dictar sentencias separadas por cada etapa. Si bien, dicha práctica fragmentaba en gran medida la integralidad del caso e incidía en la duración en el tiempo, al ser la etapa de reparaciones autónoma, permitía observar a detalle los testimonios y pruebas que acreditaban la materia (Calderón 2013, 154).

Del modo anterior, es jurídicamente la víctima quien activa todo el sistema de protección de los derechos humanos cuando una persona resiente un daño a un bien jurídico denominado derecho fundamental, que se encuentra garantizado en la normativa de relevancia, llámese Constitución o tratados internacionales.

Este criterio de apreciación coincide con la importancia de la autonomía procesal de la reparación; es decir, representa un derecho irrenunciable en tanto constituye un derecho intrínseco a la persona humana, y del cual conviene analizar su dimensión y naturaleza jurídica, sus formas de ejercerlo, sobre todo, por lo indicado en supralíneas, encontrar la forma de garantizar en el sentido más amplio de la expresión, a la persona lesionada el goce de su derecho.

Tal afirmación encuentra su fundamento en la propia Convención Americana sobre Derechos Humanos, que dispone en su artículo 63.1:

\footnotetext{
2 Voto concurrente razonado del juez Sergio García Ramírez en el caso Myrna Mack Chang vs. Guatemala, serie C, núm. 101, párr. 50, 2003. 
Cuando decida que hubo violación de un derecho o libertad protegidos en esta Convención, la Corte dispondrá que se garantice al lesionado en el goce de su derecho o libertad conculcados. Dispondrá, asimismo, si ello fuera procedente, que se reparen las consecuencias de la medida o situación que ha configurado la vulneración de esos derechos y el pago de una justa indemnización a la parte lesionada.

Adicionalmente, ha reiterado en el análisis de los casos contenciosos que ha conocido desde su primera sentencia, que "Es un principio de derecho internacional, que la jurisprudencia ha considerado «incluso una concepción general de derecho», que toda violación a una obligación internacional que haya producido un daño comporta el deber de repararlo adecuadamente" (Velázquez Rodríguez vs. Honduras, serie C, núm. 7, párr. 25, 1989).

\section{LA REPARACIÓN INTEGRAL COMO DERECHO IRRENUNCIABLE}

La indemnización, como derecho de las víctimas, constituye la forma más usual de hacerlo; pero no es limitativa, reviste especial importancia reconocer otros espacios de cumplimiento que son tarea pendiente del análisis de los derechos humanos, y sobre todo de los órganos jurisdiccionales de protección de derechos y libertades humanos.

La reparación del daño ocasionado por la infracción de una obligación internacional consiste en la plena restitución (restitutio in integrum), que incluye el restablecimiento de la situación anterior; la reparación de las consecuencias que la infracción produjo, así como el pago de una indemnización en cuanto compensación por los daños patrimoniales y extrapatrimoniales que encierran el daño moral.

Habría que añadir a lo anterior que la panorámica desde el derecho internacional constituye un referente inequívoco, observa los diversos elementos que deben cumplimentarse para la debida implementación de las medidas que deben otorgar los Estados, lo que constituye un reto, que se vincula al cumplimiento de las decisiones internacionales y a los mecanismos que permitan su recepción, implementación y ejecución interna. Es así porque la sentencia en sí misma constituye una forma de reparación, sobre todo desde el entendimiento de la tutela judicial efectiva, su incumplimiento dejaría inconcluso el ejercicio de un derecho. 
Refiriéndose a este concepto, Ferrer Mac-Gregor señala que el acceso a la justicia desde una perspectiva jurídica es un derecho fundamental, que consiste no sólo en la posibilidad formal de acudir ante los órganos del Estado encargados de impartir justicia, sino también implica que el debido proceso se respete en todas sus partes, y que lo decidido en la sentencia logre su plena realización (Ferrer 2011, 110).

De esta suerte, es posible señalar que el cumplimiento en sí mismo de la decisión judicial representa el cumplimiento de un derecho desde la perspectiva procesal de la tutela judicial efectiva, la posibilidad no sólo de acudir a un juicio, sino de que éste vea satisfechas las peticiones de la víctima de violaciones de derechos humanos, y sobre todo el cumplimiento de tal decisión que la amparen en la reparación integral.

No resulta innecesario indicar que los diversos instrumentos, incluida la Declaración Universal de los Derechos Humanos, y con especial estudio en sus setenta años, representan un punto de partida, al indicar que "toda persona tiene derecho a que se establezca un orden social e internacional en el que los derechos y libertades proclamadas en dicha Declaración se hagan plenamente efectivos". Es sabido, además, que la perspectiva del derecho internacional de los derechos humanos y del derecho constitucional tienen como objetivo primigenio el cumplimiento de los derechos en todas sus manifestaciones, pero, además, las sanciones correspondientes cuando éstos han sido desconocidos o violados.

En consecuencia, tampoco resulta ajena la jurisprudencia de la Corte Interamericana de Derechos Humanos (en adelante CoIDH), que en estos 40 años de funcionamiento ha emitido un gran número de resoluciones encaminadas a dar respuesta a las necesidades de las víctimas, aunado al reconocimiento de la dignidad, protección y garantía de los derechos de las víctimas. Su labor de interpretación ha permitido el desarrollo doctrinal del concepto de la reparación integral.

La Corte Interamericana ha establecido que las reparaciones deben tener un nexo causal con los hechos del caso, las violaciones declaradas, los daños acreditados, así como las medidas solicitadas para reparar los daños respectivos. ${ }^{3}$

El alcance de la reparación integral contenido en el artículo 63.1 debe evaluarse de manera autónoma, por lo que la construcción teórica sobre el concepto de justicia y el derecho a la verdad cobra sentido a la luz de su

3 Mujeres Victimas de Tortura Sexual en Atenco vs. México, serie C, núm. 371, párr. 327, 2018.

Esta obra está bajo una Licencia Creative Commons

Atribución-NoComercial-SinDerivar 4.0 Internacional, IIJ-UNAM.

Boletín Mexicano de Derecho Comparado, núm. 157, enero-abril de 2020, pp. 333-352. 
contenido, el deber del Estado de repararlo integralmente, y sus diversas modalidades, ya sea individual o colectivamente. Desde luego, no pasa inadvertido que la restitución integral desde el punto de vista material puede representar una imposibilidad fáctica en algunos casos, sobre todo considerando aquellos que son irreparables de manera absoluta.

En lo que respecta al artículo 63.1 de la Convención Americana, la Corte ha indicado que esta disposición recoge una norma consuetudinaria, que constituye uno de los principios fundamentales del derecho internacional contemporáneo sobre la responsabilidad de los Estados. De esta manera, al producirse un hecho ilícito imputable a un Estado, surge de inmediato la responsabilidad internacional de éste por la violación de una norma internacional, con el consecuente deber de su reparación y de hacer cesar las consecuencias de la violación; es decir, bajo una interpretación progresiva existe una obligación de cumplimiento de los deberes generales que representa todo tipo de tratados internacionales vinculados con los derechos humanos y, segundo, el derecho que asiste a la víctima que resiente tal afectación.

La reparación del daño ocasionado por la infracción de una obligación internacional requiere, siempre que sea posible, la plena restitución, que consiste en el restablecimiento de la situación anterior. De no ser esto posible, como en algunos casos, cabe al tribunal internacional determinar una serie de medidas para, además de garantizar los derechos conculcados, reparar las consecuencias que las infracciones produjeron, así como establecer el pago de una indemnización como compensación por los daños ocasionados. ${ }^{4}$

Esta posición posee resonancia significativa, pues se encamina a recordar en estos 70 años de derechos, que la reparación integral constituye un derecho irrenunciable, y que comprende la realización de diversos elementos, como la restitución, que pretende devolver a la víctima a la situación anterior a la violación, y que además incluye no sólo la restitución material, sino también la restitución de los derechos. Desde la óptica que la centralidad es el sujeto de derechos en un contexto determinado y no necesariamente al revés, es posible entender que cualquier violación debe resarcir el daño ocasionado a la víctima, además de determinar la posible responsabilidad internacional del Estado, e inclusive hacer visible

\footnotetext{
4 Bámaca Velásquez vs. Guatemala, serie C, núm. 70, párr. 40, 2000.
} 
una eventual problemática estructural en determinada región que evite violaciones masivas futuras.

Por ello, conviene apuntar desde una lectura del artículo 1o. de la Constitución, cuáles son las obligaciones generales del Estado en materia de derechos humanos. La respuesta es sencilla: respetar, proteger, garantizar y promover los derechos humanos, así como la vinculación con los principios de aplicación, como son los contenidos esenciales, la progresividad, la prohibición y, en su caso, el máximo uso de recursos disponibles para satisfacer de manera integral a las aflicciones de la víctima.

El propio tribunal interamericano ha señalado que los Estados tienen dentro de sus obligaciones proporcionar a los individuos los medios de protección de los derechos humanos reconocidos internacionalmente, que incorpora medidas de prevención y protección de los actos de autoridades y, en su caso, de los particulares. De conformidad con ello, existe una obligación convencional de respetar los derechos garantizados tanto a nivel de la Constitución como de los tratados internacionales. ${ }^{5}$

Es oportuno puntualizar que no basta que los Estados se abstengan de violar derechos, sino que además hace falta la adopción de medidas positivas, determinables en función de las particulares necesidades de protección del sujeto de derecho, considerando sobre todo a los grupos más desaventajados social y económicamente.

El deber de prevenir (así lo ha señalado el tribunal regional), abarca todas aquellas medidas de carácter jurídico, político, administrativo y cultural que promuevan la salvaguarda de los derechos humanos, y que aseguren que todas las violaciones que fueran cometidas sean beneficiarias de una reparación integral. Tal es el supuesto que las eventuales violaciones a los mismos deben ser efectivamente consideradas y tratadas como un hecho ilícito que, como tal, es susceptible de acarrear sanciones para quienes los cometan. ${ }^{6}$

Por su parte, las víctimas tienen el derecho de exigir la persecución, enjuiciamiento, condena y esclarecimiento de la verdad y reparación de las violaciones generadas por la comisión de crímenes de lesa humanidad, especialmente en caso de que sean perpetrados por agentes estatales. ${ }^{7}$

5 Masacre del Pueblo Bello vs. Colombia, 2006, serie C, núm. 140 párr. 123; Masacre de Maripipán vs. Colombia, 2005 serie C, núm.134, párr. 19.

6 Gonzáles y otras “Campo Algodonero" vs. México, serie C, núm. 205, párr. 252, 2008.

7 Almonacid Arellano y otros vs. Chile, serie C, núm. 154, párr. 111, 2006. 
Adicional a este planteamiento, señalaríamos que el deber de investigación y sanción conlleva al real y efectivo acceso a la justicia, porque una justicia que no consigue la reparación, no representa una garantía plena.

\section{ELEMENTOS DE LA REPARACIÓN INTEGRAL DEL DAÑO}

La restitución como elemento indispensable de la reparación, incorpora medidas como el restablecimiento de la libertad, la restitución de bienes o valores, la reincorporación de la víctima a su cargo y el pago de salarios dejados de percibir, la recuperación de la identidad y la restitución del vínculo familiar; devolución de tierras tradicionales a los miembros de la comunidad indígena, extracción segura de explosivos enterrados en el territorio indígena y reforestación de áreas afectadas, entre algunas (Calderón 2013).

Esta medida tiene por objetivo último devolver las cosas al estado en que se encontraban antes de la comisión de la violación. Por su parte, en cuanto a los elementos de la rehabilitación como obligación del Estado, concierne la reparación de las afectaciones síquicas o morales que pueden ser motivo de tratamiento o asistencia médica y sicológica a cargo de la autoridad, lo cual debe realizarse de manera gratuita e inmediata.

La Corte Interamericana dispone que, de no ser factible, como ocurre en la mayoría de los casos de violaciones a derechos humanos, dicho tribunal determinará las medidas para garantizar los derechos conculcados y reparar las consecuencias que las infracciones produjeron. ${ }^{8}$ Este enunciado nos permite entender que el órgano de garantía podrá implementar medidas y exigir responsabilidades concretas con el fin de restituir a la víctima.

Dicho tribunal ha sido enfático al indicar que la impunidad es la falta en su conjunto de investigación, persecución, captura, enjuiciamiento y condena de los responsables de las violaciones de los derechos protegidos por la Convención Americana, toda vez que el Estado tiene la obligación de combatir tal situación por todos los medios legales disponibles, tomando en cuenta que la impunidad propicia la repetición crónica de las vio-

8 Velázquez Rodríguez vs. Honduras. Reparaciones y costas, serie C, núm. 7, párr. 26,1989; López Soto y otros vs. Venezuela, Fondo, reparaciones y costas, serie C, núm. 362, párr. 269, 2018. 
laciones a derechos humanos y la total indefensión de las víctimas y sus familiares. ${ }^{9}$

Con profundidad de análisis, la obligación de investigar conlleva la necesidad de que una vez que las autoridades estatales tengan conocimiento del hecho, deban iniciar una investigación seria, imparcial y efectiva de manera oficiosa, que permita la determinación de la verdad y, en su caso, la sanción de los autores de la violación. Esta medida se traduce en el acceso a la justicia en su más amplia concepción, y cuyo objetivo principal sea calar en el ordenamiento nacional.

La indemnización refiere una compensación determinada en una norma jurídica por el daño resentido; ésta debe comprender por lo menos el daño emergente y el lucro cesante, además de añadir las medidas de carácter positivo para asegurar que no se repitan hechos lesivos.

La obligación de investigar conlleva además que el Estado debe asegurar el pleno acceso y capacidad de actuar de las víctimas o sus familiares en todas las etapas de la investigación y el juzgamiento de los responsables, de acuerdo con la ley interna y las normas de la Convención Americana. Investigar representa además el que la sociedad conozca la verdad y quiénes fueron los perpetradores de los crímenes cometidos.

Se ha destacado que el deber de investigación y enjuiciamiento subsiste mientras no se alcance el objetivo al que sirve; esto es, el pleno conocimiento de los hechos, la identificación de los autores y la sanción que corresponda (García y Benavides 2014). En el caso Hermanas Serrano Cruz vs. El Salvador, la Corte Interamericana señaló que "es una obligación que corresponde al Estado siempre que haya ocurrido una violación de los derechos humanos y esa obligación debe ser cumplida seriamente y no como una mera formalidad". ${ }^{10}$

Las medidas de no repetición, por su parte, se enfocan a la garantía para prevenir otra violación de otras personas; así lo dispone en el caso Masacre de las Dos Erres "con el fin de evitar que en el futuro se produzcan hechos similares, conforme al deber de prevención y garantía de los derechos fundamentales reconocidos en la Convención Americana". ${ }^{11}$

En el ámbito de la prevención, procede mencionar que ésta se encuentra ligada a la investigación que arroja resultados de quiénes come-

9 Almonacid Arellano y otros vs. Chile, serie C, núm. 154, párr. 111, 2006.

10 Hermanas Serrano Cruz vs. El Salvador, serie C, núm.120, párr. 168, 2005.

11 Masacre de Las Dos Erres vs. Guatemala, serie C, núm. 2011, párr. 250, 2009. 
tieron las violaciones y a su vez la forma de evitar que se sigan cometiendo, por ejemplo, implementando medidas legislativas que sancionen las violaciones a los autores intelectuales, o bien programas de capacitación y formación en materia de derechos humanos.

Es atinado mencionar que este tipo de medidas son complejas y estructurales, y van encaminadas a reformas normativas y a la implementación de políticas que orienten a la prevención de violaciones futuras; podrían señalarse, por ejemplo, la exclusión de penas corporales que atenten contra la dignidad de las personas, la existencia de normas de pena de muerte, la invalidez de normas jurídicas que se encaminen a obstaculizar procesalmente las sanciones por violaciones graves a los derechos humanos, modificación de normas en materia de jurisdicción militar, entre otras.

Lo cierto es que el deber estatal de respeto y garantía tiene una aspiración manifiesta sobre el deber de justicia, la existencia misma de condiciones para el acceso a la justicia y para la sanción y reparación de violaciones a derechos humanos que erosione la impunidad y propicie de forma enérgica el cumplimiento de las disposiciones contenidas en la Constitución y los tratados internacionales.

\section{GUMPLIMIENTO DE SENTENGIAS INTERNAGIONALES COMO ELEMENTO FUNDAMENTAL DE LA REPARACIÓN}

Como lo he señalado en anteriores documentos (Verdín 2019), el cumplimiento de las decisiones internacionales representa un enorme desafio a nivel interno e internacional, y pretendemos sostener que existe una vinculación importante entre la ejecutabilidad de las decisiones internacionales y la efectividad de los derechos fundamentales.

Cuando un órgano internacional ordena medidas provisionales o en su caso dicta resoluciones judiciales, por un lado, para identificar que el Estado ha cometido una violación y, por el otro, con el fin último de dar cumplimiento a la Convención Americana sobre Derechos Humanos y dar efectividad plena a los derechos de las personas, los Estados de conformidad con el artículo 68 de la Convención Americana, deberán ejecutar los fallos.

Surgen puntos controvertidos al tenor de la anterior afirmación, ya que con el fin de dar cumplimiento a dicho mandato, algunos Estados han diseñado métodos de ejecución de las sentencias de tribunales internacionales, 
inclusive algunos protocolos, que incluyen aspectos procedimentales para facilitar su actuación, considerando las convergencias y divergencias de los sistemas jurídicos existentes que los regulan, lo cierto es que algunos sólo dan cumplimiento parcial o casi nulo, subsistiendo la afectación a la víctima y obligándonos a representar el ideal de "justicia" como algo inexistente.

Como ejemplo de aquellos que han diseñado medidas para dar cumplimiento y ejecutarlas, encontramos al Protocolo 11 del Tribunal Europeo de Derechos Humanos, adoptado en octubre de 1997, que determinó la eliminación de la Comisión Europea de Derechos Humanos, con lo cual la Corte fue restructurada. En dicha resolución, nos indica Salvador Mondragón Reyes, que, respecto de la ejecución de las resoluciones de esta Corte, el artículo 41 de la Convención Europea señala:

Si el Tribunal declara que ha habido violación del Convenio o de sus protocolos y si el derecho interno de la Alta Parte Contratante sólo permite de manera imperfecta reparar las consecuencias de dicha violación, el Tribunal concederá a la parte perjudicada, si así procede, una satisfacción equitativa (Mondragón 2007, 74).

Empero, no basta la existencia de un fallo internacional, o la realización de actuaciones poco estructuradas e irrelevantes, sino que es conveniente que el Estado dé cumplimiento al mismo, y este presupuesto se vincula con el régimen de la reparación integral, pues en sí mismo el cumplimiento de un fallo condenatorio al Estado miembro representa una parte indispensable de la reparación plena.

El mismo autor señala que existen algunos países que han diseñado procedimientos que faciliten la ejecutabilidad y cumplimiento de las sentencias; por ejemplo, en Alemania, el papel clave lo tienen las cortes, ya que se consideran guardianes de Estado de derecho. Dicha afirmación coincide con la del suscrito, en virtud de que consideramos que el papel dotado a los tribunales constitucionales en esa tradición asumida desde 1920, por inspiración de Hans Kelsen, resulta prometedor, en la medida de propiciar un vaso comunicante entre las cortes nacionales y las cortes internacionales de manera más pacífica y gradual.

Algunas sugerencias apuntan a indicar que, con independencia de las propias resistencias de los sistemas, es la universalidad de los derechos humanos y la naturaleza de los bienes protegidos, los cuales confluyen en 
la dignidad de las personas y en el papel decisivo de las cortes nacionales que permiten y obligan a dar cumplimiento a una decisión de gran calado para la reparación integral.

Otros Estados han optado por incluir normas de ejecución en sus Constituciones federales, o inclusive por vía de interpretación del derecho internacional en el derecho nacional; un ejemplo de ello corresponde a la propia interpretación que ha realizado nuestra Suprema Corte de Justicia de la Nación en algunos criterios jurisprudenciales. ${ }^{12}$

Lo cierto es que resulta necesario identificar las diferencias entre ejecución, cumplimiento, impacto y reparación integral; todos estos elementos definitivos para equilibrar los contenidos de los derechos humanos, impedir las interferencias procesales que traducen en ilusorios los derechos y libertades de las personas.

Es contundente la interpretación que ha hecho la Corte mexicana al señalar que los derechos humanos en su conjunto constituyen el parámetro de control de regularidad constitucional, conforme al cual debe analizarse la validez de las normas y actos que forman parte del orden jurídico mexicano.

En nuestro supuesto, la jurisdicción de la Corte Interamericana de Derechos Humanos es aceptada por el Estado mexicano, y, por lo tanto, cuando se esté en incumplimiento de las obligaciones expresamente contraídas por éste, el tribunal constitucional ha considerado que no corresponde a la Suprema Corte de Justicia de la Nación analizar, revisar, calificar o decidir si una sentencia dictada por aquel organismo internacional es correcta o no, lo que debe entenderse en forma unímoda y dogmática, ya que la competencia del máximo tribunal constitucional del país, como garante de la supremacía constitucional, descansa ontológica e inmanentemente en su actuación, de acuerdo con el artículo 133 de la Constitución Política de los Estados Unidos Mexicanos. ${ }^{13}$

De conformidad con ello, las relaciones entre los dos sistemas dan lugar al enunciado imperativo del cumplimiento de las decisiones internacionales, lo cual orienta la labor interna de la interpretación de los derechos humanos y tiende a garantizar la efectividad de los derechos del hombre.

12 Tesis 293/201 1, P./J. 20/2014 (10a.), Gaceta del Semanario Fudicial de la Federación, 2014.

13 Tesis P.LXV/2011 (9a.), Gaceta del Semanario Fudicial de la Federación, 2011. 
Es un imperativo el deber del Estado de adecuar su derecho interno a las disposiciones de la Convención Americana, con el propósito de prevenir y sancionar las conductas violatorias de los derechos humanos, deber que resulta de la obligación de respeto y garantía contenida en dichos tratados internacionales; en ese tenor, los fallos emitidos por tales instancias internacionales deben cumplirse y ejecutarse.

\section{CONCLUSiOnes}

Es verdad que existe una importante área de oportunidad para el análisis de los derechos humanos y la forma de dar cumplimiento a ellos; la genealogía de los compromisos internacionales permite asumir una tarea valiosa en el ámbito de la reparación integral.

Se presume la buena fe de los Estados para dar cumplimiento a sus resoluciones internacionales y con ello agotar una etapa en la reparación integral, en virtud de que el cumplimiento del fallo internacional es parte misma de la reparación. Asimismo, se confirma la estrecha relación que existe entre la reparación integral del daño y el cumplimiento de los fallos internacionales, lo cual arroja como resultado el "acceso a la justicia".

En el marco de los 70 años de la Declaración Universal y los 40 de la actividad de la Corte Interamericana, es indispensable la discusión en torno al derecho a la reparación como un derecho procesal y autónomo, capaz de establecer su naturaleza genuina y evaluar los alcances jurídicos de un comportamiento ilícito que vulnere los derechos y libertades intrínsecas de las personas.

Del mismo modo, se asume que el concepto de víctima es la columna vertebral de cualquier sistema de protección de derechos humanos, y ha desarrollado con profundidad toda una doctrina sobre las reparaciones, que contempla no sólo la indemnización, sino que también determina responsabilidades concretas a la luz de las obligaciones en torno al respeto y garantía.

No pasa inadvertida la preocupación del autor al indicar que el incumplimiento de los fallos internacionales ha guiado el estudio presente, pues representan la esterilidad del derecho a la verdad y justicia y conducen a considerar medidas necesarias que implementar al interior del Estado para dar cumplimiento puntual y efectivo que evite violaciones sistemáticas futuras.

Esta obra está bajo una Licencia Creative Commons

Atribución-NoComercial-SinDerivar 4.0 Internacional, IIJ-UNAM.

Boletín Mexicano de Derecho Comparado, núm. 157, enero-abril de 2020, pp. 333-352. 
En suma, la orientación principal del breve estudio que aquí se plasma se encuentra destinada a conmemorar estas fechas relevantes para los derechos humanos, y además discutir sobre los importantes desafíos que representa para cualquier sistema de protección, ya sea interno o internacional, el régimen de las reparaciones por violaciones a derechos humanos, así como el alcance que tales medidas pueden tener para evitar la impunidad y la repetición crónica y estructural de tales ilícitos.

\section{BIBLIOGRAFÍA}

Calderón GambOA, Jorge F. 2013. "La reparación integral en la jurisprudencia de la Corte Interamericana de Derechos Humanos: estándares aplicables al nuevo paradigma mexicano", en FERRER MACGregor, Eduardo et al., Derechos humanos en la Constitución. Comentarios de jurisprudencia constitucional e Interamericana, México, SCJN-UNAM-Konrad Adenauer.

Corzo SosA, Edgar et al. (coords.) 2013. Impacto de las sentencias de la Corte Interamericana de Derechos Humanos, México, Tirant lo Blanch.

FERRER MAG-GregOr, Eduardo. 2011. "La justicia y el constitucionalismo social”, en FIX-ZAMUdIO, Héctor y VALADÉS, Diego, Instituciones sociales en el constitucionalismo contemporáneo, México, UNAM, Instituto de Investigaciones Jurídicas.

García Ramírez, Sergio y Benavides Hernández, Marcela. 2014. Reparaciones por violación a derechos humanos. Furisprudencia Interamericana, México, Porrúa.

GARCía RAMíREz, Sergio. 2016. "Víctima y reparaciones en la jurisprudencia de la Corte Interamericana", en NATARÉn NANDAYAPA, Carlos F. et al. (coords.). Las víctimas en el sistema penal acusatorio, México, UNAM, Instituto de Investigaciones Jurídicas, USAID.

GonzÁlez Rodríguez, Patricia y Witker, Jorge. 2019. Desafios del sistema penal acusatorio, México, UNAM.

HitTERs, Juan Carlos. 2011. "El control de convencionalidad y el cumplimiento de las sentencias de la Corte Interamericana (supervisión supranacional. Cláusula federal)", Revista Uruguaya de Derecho Procesal, núm. 2.

LONDOÑo LÁzARO, María Carmelina. 2005. "La efectividad de los fallos de la Corte Interamericana de Derechos Humanos", Dikaíon, año 19, núm. 14. 
Mondragón Reyes, Salvador. 2007. Ejecución de las sentencias de la Corte Interamericana de Derechos Humanos, México, Porrúa.

NASH Rojas, Claudio. 2009. Las reparaciones ante la Corte Interamericana de Derechos Humanos (1988-2007), 2a. ed., Santiago, Universidad de Chile, Facultad de Derecho.

Petrova Georgieva, Virdzhiniya. 2019. Los principios comunes a los tribunales internacionales, México, UNAM, Instituto de Investigaciones Jurídicas.

Pinacho EsPinOSA, Jacqueline. 2019. El derecho a la reparación del daño en el sistema interamericano, México, Comisión Nacional de los Derechos Humanos.

SAAVEDRA ÁlVAREz, Yuria. 2013. "Teoría de las reparaciones a la luz de los derechos humanos", Metodología para la enseñanza de la reforma constitucional en materia de derechos humanos, módulo 7, México, Comisión de Derechos Humanos del Distrito Federal-SCJN.

Verdín PÉREZ, Jaime Arturo. 2019. "La eficacia del fallo internacional en derechos humanos en el sistema interamericano de protección de derechos humanos", Boletín Mexicano de Derecho Comparado, núm. extraordinario, 2019 (51). 